nimmt, denn die alkoholische Lösung des entfärbten Scammoniumharzes wird durch Säuren eben so wenig wie diejenige des gereinigten Jalappenharzes getrübt. (Buchn. Repert. Bd.3. 1.)

B.

\title{
Ueber die Bereitung und Anwendung des Upasgiftes in Ostindien.
}

Dr. Lilienfeld, ehemals in Ostindien, veröffentlicht darüber Folgendes:

Es ist über den Upasbaum und den Saft desselben bis jetzt so viel gefabelt worden, dass es nöthig erscheint, etwas Zuverlässiges darüber mitzutheilen.

Der Upas- oder Antiarbaum, Antiaris toxicaria von Lechenault (Pohon-Upas vom Inländer) genannt, ist einer der grössten Bäume Ostindiens und hat oft einen Durchmesser von 6-8 Fuss; seine Höhe beträgt alsdann 60-70 Fuss. Die Rinde ist weissgrau und beim Einschneiden derselben fliesst ein Saft aus, welcher an der Luft schnell hart und braun wird. Dieser Saft ist für sich allein durchaus nicht giftig, sondern er wird es erst durch Vermischung mit andern Pflanzensäften. Man nimmt 8 Unzen des Upassaftes und vermengt damit den Saft von Rumpheria Galanga, Zerumbet, $Z$ wiebeln und Knoblauch ana 1 Drachme und 2 Drachmen gestossenen Pfeffer. Diese Mischung fängt augenblicklich an $\mathrm{zu}$ gähren, und je stärker das Aufbrausen, desto wirksamer ist das Gift.

Der Aufenthalt unter dem Upasbaum ist keineswegs tödtlich oder selbst nur schädlich.

Die Japaner und Malayen gebrauchen gegenwärtig nur noch höchst selten das Upasgift zum Vergiften ihrer Waffen, während das Vergiften der Pfeile bei den Dajakkern in Borneo noch allgemein im Gebrauch ist. (Casp. Vierteljahrsschrift. Bd.3. - Buchn. Repert. Bd.3. H. 1.)

$B$.

\section{Ueber californische Muskatnüsse.}

Vor etwa einem Jahre erhielt Torrey durch Shelton, nach dessen Rückkehr aus Californien, eine Probe von den sogen. californischen Muskatnüssen. Dieser Baum war erst 1 oder 2 Jahre vor der Abreise Shelton's in Californien entdeckt, und schon in dieser kurzen Zeit hat er, nicht bloss wegen seiner Schönheit, sondern auch wegen der Eigenthümlichkeit der Frucht und der Kerne, 
alle Aufmerksamkeit auf sich gezogen. Tor re y bestimmt den Baum als zur Gattung Torreya Arnott's (Taxineae) gehörig. Die Beblätterung des Baumes hat das Dunkelgrün der Florida-Species, d. i. Torreya taxifolia, aber die Blätter sind 1//2 -2 Zoll lang. Sie breiten sich nach zwei Richtungen aus und enden in einer scharfen, steifen Spitze. Die Frucht hat in trockenem Zustande eine blasse Olivenfarbe, doch mag diese nicht die natürliche sein. Die äussere Hülle ist ein dicker, fleischiger, fast geschlossener Krtg, der den Samen vollständig bekleidet und überall, mit Ausnahme des Gipfels, fest an ihm haftet. Sie ist glatt und sanft anzufühlen. Der Samen ist meist oblong oder etwas eiförmig, seine Schale glatt, dünn und zerbrechlich. An einer Seite und dicht unter der Stelle, die von der Fruchthülle frei ist, ist eine Durchbohrung, die mit einem innern Canale communicirt, so wie Torrey es auch bei T. taxifolia fand, dessen Bedeutung nicht bekannt ist. Der Kern des Samens ist der äussern Schale desselben conform und sieht innen und aussen wie eine Muskatnuss aus, auf dem Querdurchschnitt vollständig so. Das angenehme Aroma der eigentlichen Muskatnuss fehlt aber ganz. Der Samen riecht terpentinartig und lässt seine Abstammung von einer Conifere nicht verkennen.

Die äussere Fruchthülle hat keinerlei Anwendung, sie ist vielleicht, wie die der Taxusfrucht, giftig. Jedenfalls ist die Entdeckung von botanischem Interesse. Nur zwei Arten sind bis jetzt bekannt: T. nucifera Lieb. et $Z$. in Japan, und die andere, die sich auf einem sehr beschränkten Raume in Mittel-Florida findet.

Die californische Species verdient jedenfalls weiter durch Anbau verbreitet $\mathrm{zu}$ werden, da sie ein kälteres Klima verträgt.

Die von Parson's et Comp. von Flushing von diesem Baume eingesandten reifen und frischen Samen wurden angelegt, sie keimten ohne Weiteres, und als Torrey die jungen Pflanzen im October sah, hatten sie bereits eine ansehnliche Grösse. Torrey nennt diese Pflanze: Torreya californica, foliis distichis brevissime petiolatis cuspidatis pungentibus subconcoloribus, floribus foemineis solitariis serrilibus, seminibus oblongis, disco carnoso clauso. Wächst an den oberen Theilen der Yuba und Feather Rivers, am westlichen Abhange der Sierra Novada von Californien. (New York Jourm. of Pharm. Vol. 3.-Chem.pharm. Centrbl. 1854. No. 19.)

$B$.

Arch. d. Pharm. CXXXI.Bds. 1.Hft. 